\title{
Determining optimal dosing regimen of oral administration of dicloxacillin using Monte Carlo simulation
}

This article was published in the following Dove Press journal:

Drug Design, Development and Therapy

28 June 2017

Number of times this article has been viewed

\author{
Wei $\mathbf{Y u}^{1,2, *}$ \\ Jinru Jil,* \\ Tingting Xiao' \\ Chaoqun Ying' \\ Jiaheng Fang ${ }^{3}$ \\ Ping Shen' \\ Yonghong Xiao'
}

'State Key Laboratory for Diagnosis and Treatment of Infectious Diseases, Collaborative Innovation Center for Diagnosis and Treatment of Infectious Diseases, The First Affiliated Hospital, College of Medicine, Zhejiang University, ${ }^{2}$ Department of Infectious Diseases, Zhejiang Provincial People's Hospital, ${ }^{3}$ Department of Gastroenterology, Hang Zhou Normal University Affiliated Hospital, Hangzhou, People's Republic of China

*These authors contributed equally to this work
Correspondence: Yonghong Xiao State Key Laboratory for Diagnosis and Treatment of Infectious Diseases, Collaborative Innovation Center for Diagnosis and Treatment of Infectious Diseases, The First Affiliated Hospital, College of Medicine, Zhejiang University, 866 Yuhangtang Road, Hangzhou,

Zhejiang Province, 310058, People's

Republic of China

$\mathrm{Tel}+8657187236421$

Fax +86 57| 8723 642I

Email xiao-yonghong@।63.com
Background: Dicloxacillin, a semisynthetic isoxazolyl penicillin, exhibits antimicrobial activity against a wide variety of Gram-positive bacteria, as well as stability against penicillinases and low level of toxicity. The objective of this study was to obtain optimal dosing regimen of oral administration of dicloxacillin by analyzing the pharmacokinetic (PK) index in healthy volunteers and in vitro antibacterial activity by using Monte Carlo simulation.

Materials and methods: A total of 867 clinical isolates from community-onset infections were collected from 31 secondary hospitals in People's Republic of China. The minimum inhibitory concentration (MIC) values of dicloxacillin were determined by the agar dilution method. Based on the MICs and the PK parameters of different dosage regimens, Monte Carlo simulation was performed to simulate the $\mathrm{PK} /$ pharmacodynamic indices of $250 \mathrm{mg}$ once-daily (qd), $500 \mathrm{mg} \mathrm{qd}$, $1,000 \mathrm{mg} \mathrm{qd}, 2,000 \mathrm{mg} q d, 250 \mathrm{mg}$ every 6 hours (q6h), and $500 \mathrm{mg}$ q6h, respectively. The probability of target attainment was estimated at each MIC value, and the cumulative fraction of response (CFR) was calculated to evaluate the efficacy of these regimens.

Results: Dicloxacillin showed poor antibacterial activity against Haemophilus influenzae, Moraxella catarrhalis, and Streptococcus pneumoniae. Resistance to dicloxacillin was observed in $7.5 \%$ of coagulase-negative Staphylococcus (CNS) isolates and 9.2\% of other Streptococcus isolates, whereas $1.5 \%$ of methicillin-sensitive Staphylococcus aureus (MSSA) was resistant to dicloxacillin. Multiple-dose regimens could obtain higher CFR than single-dose regimens against $H$. influenza and $S$. pneumoniae. However, all dosing regimens against MSSA achieved CFR $\geq 90 \%$. Meanwhile, dosing regimen of 2,000 $\mathrm{mg} \mathrm{qd}, 250 \mathrm{mg}$ q6h, and $500 \mathrm{mg}$ q6h could achieve $>90 \%$ of CFR for CNS. For other Streptococcus isolates, multiple-dose regimens achieved CFR $\geq 90 \%$.

Conclusion: Dicloxacillin has a significant antibacterial activity against MSSA, CNS, and other Streptococcus isolates. The simulation results suggest that dicloxacillin $250 \mathrm{mg}$ q6h and $500 \mathrm{mg}$ q6h dosing regimens may be recommended for clinical applications, especially for community-onset infections.

Keywords: pharmacokinetics, pharmacodynamics, PK/PD index, dosage regimens, MSSA, CNS

\section{Introduction}

Dicloxacillin, as a semisynthetic penicillin antibiotic, acts by inhibiting the biosynthesis of bacterial cell walls. It is used in the treatment of infections caused by susceptible Gram-positive bacteria, especially for mild-to-moderate Staphylococcal infections. ${ }^{1-3}$ It is worthy of note that dicloxacillin is insensitive to $\beta$-lactamase secreted by many penicillin-resistant bacteria. ${ }^{4}$ The main cause lies in the presence of the isoxazolyl group on the side chain of the penicillin nucleus with relatively intolerant side-chain 
steric hindrance, resulting in unbound or inactivated $\beta$-lactamase..$^{5}$ In addition, several retrospective studies showed that definitive therapy for penicillinsusceptible Staphylococcus aureus bacteraemia with dicloxacillin was associated with a significantly lower mortality than was associated with cefuroxime therapy. ${ }^{6,7}$

In an era of increasing resistant pathogens prevalence, pharmacokinetics/pharmacodynamics (PK/PD) theory is helpful in optimizing the antimicrobial therapy to patients. ${ }^{8}$ Studies on $\beta$-lactams against organisms have demonstrated that successful treatment outcome is associated with timedependent bactericidal activity, and the efficacy of penicillins is dependent on the amount of time during which the serum drug concentration exceeds the minimum inhibitory concentration (MIC) of the antibiotic ( $\% T>$ MIC). The optimal PKPD target of $\% T>$ MIC has been estimated to be $40 \%$ for penicillins. ${ }^{9}$

Monte Carlo simulations are mainly used in three distinct problem classes: optimization, numerical integration, and generating draws from a probability distribution. The clinical probability of success for different dosing regimens of antibiotics can be predicted by Monte Carlo simulation. ${ }^{10,11}$ Dicloxacillin is not marketed in Mainland China; however, the safety and PK data for a generic formulation of dicloxacillin sodium in healthy Chinese volunteers have been published in 2015. ${ }^{12}$ Therefore, the primary objective of this study was to combine the results of $\mathrm{PK}$ with antibacterial activity to explore reasonable dosage regimens of dicloxacillin by using Monte Carlo simulation. The results will be provided as a basis for rational use of dicloxacillin in Chinese population in further clinical applications.

\section{Materials and methods}

\section{Bacterial isolates}

A total of 867 clinical isolates from community-onset infections were collected between August 2010 and December 2011 from 31 secondary hospitals in People's Republic of China.
Haemophilus influenzae $(\mathrm{n}=54)$, Moraxella catarrhalis ( $\mathrm{n}=56)$, methicillin-sensitive $S$. aureus (MSSA; n=388), coagulase-negative Staphylococcus (CNS; n=53), Streptococcus pneumoniae $(\mathrm{n}=262)$, and other Streptococcus isolates (ie, $\beta$-hemolytic streptococcus, Streptococcus anginosus, Streptococcus constellatus, Streptococcus dysgalactiae, Streptococcus agalactiae, Streptococcus pyogenes, and Streptococcus viridans; $\mathrm{n}=54$ ) were included. Pathogens were isolated by using standard microbiological methods and identified by using API20 (bioMérieux, Durham, NC, USA). Isolates that had MIC of oxacillin $\leq 2$ were identified as MSSA. All the pure cultures were frozen at $-80^{\circ} \mathrm{C}$ and shipped to our central laboratory for definite identification and further analysis. Identification of species was ratified by Matrix-assisted laser desorption ionization-time-of-flight mass spectrometry (VITEK ${ }^{\circledR}$ MS; bioMérieux, Nürtingen, Germany) as described previously. ${ }^{13}$ Table 1 shows the basic characteristics of the isolates.

\section{Antimicrobial susceptibility testing}

The MICs for dicloxacillin (Bright Future Pharmaceuticals Factory, Hong Kong, People's Republic of China) were determined by the agar dilution method according to Clinical and Laboratory Standards Institute (CLSI) ${ }^{14}$ The results were interpreted according to oxacillin interpretive standards of CLSI criteria ( $\leq 2 \mathrm{mg} / \mathrm{L}$ susceptible; $\geq 4 \mathrm{mg} / \mathrm{L}$ ). Escherichia coli American Type Culture Collection (ATCC) 25922 and S. aureus ATCC 29213 were used as quality controls.

\section{Monte Carlo simulation}

Dicloxacillin, like other penicillins, displays time-dependent $\mathrm{PD}$, and the bactericidal effect of it best correlates with \%T> MIC. ${ }^{9}$ In the present study, we simulated different dosing interval PK/PDs on the basis of a previous PK trial. ${ }^{12}$ $\% T>$ MIC of $40 \%$ has been identified as the target for nearmaximal bacterial killing. ${ }^{9}$ In order to obtain the probability of target attainment (PTA) of MIC, the Crystal Ball software

Table I Basic characteristics of 867 clinical isolates

\begin{tabular}{|c|c|c|c|c|c|c|c|c|c|c|}
\hline \multirow[t]{2}{*}{ Isolates } & \multicolumn{2}{|c|}{$\operatorname{Sex}(n)$} & \multirow[t]{2}{*}{ Age (years) } & \multicolumn{7}{|c|}{ Infection site (n, \%) } \\
\hline & $\mathbf{F}$ & $\mathbf{M}$ & & as & bl & dr & se & sp & ur & csf \\
\hline Haemophilus influenzae $(n=54)$ & 20 & 34 & $6(1-32)$ & - & - & - & - & $54(100 \%)$ & - & - \\
\hline Moraxella catarrhalis $(\mathrm{n}=56)$ & 27 & 29 & $2(6 m-4)$ & - & - & - & - & $56(100 \%)$ & - & - \\
\hline MSSA $(n=388)$ & 171 & 217 & $27(6-48)$ & $142(36.6 \%)$ & $28(7.2 \%)$ & $3(0.8 \%)$ & $132(34.0 \%)$ & $76(19.6 \%)$ & 7 (I.8\%) & - \\
\hline CNS $(n=53)$ & 30 & 23 & $30(18-43)$ & $2(3.8 \%)$ & $20(37.7 \%)$ & $2(3.8 \%)$ & II (20.8\%) & $2(3.8 \%)$ & $12(22.6 \%)$ & $4(7.5 \%)$ \\
\hline Streptococcus pneumoniae $(n=262)$ & 87 & 173 & $3(I-55)$ & - & $3(1.1 \%)$ & $2(0.8 \%)$ & $3(1.1 \%)$ & $248(94.7 \%)$ & $2(0.8 \%)$ & $4(1.5 \%)$ \\
\hline Other Streptococcus isolates $(n=54)$ & 29 & 25 & $36(18-52)$ & $13(24.1)$ & $3(5.6 \%)$ & $2(3.7 \%)$ & $13(24.1 \%)$ & $16(29.6 \%)$ & $7(13 \%)$ & - \\
\hline
\end{tabular}

Note: '-' indicates no specimen.

Abbreviations: as, abscess; bl, blood; CNS, coagulase-negative Staphylococcus; csf, cerebrospinal fluid; dr, drainage; F, female; M, male; m, month; MSSA, methicillin-sensitive Staphylococcus aureus; se, secretion; sp, sputum; ur, urine. 
was used to perform a 10,000 subject Monte Carlo simulation (MICs obey the discrete distribution, the PK index, volume of distribution, and half-life obey log-normal distribution). According to the PK index of different dosage regimens and MIC results, Monte Carlo simulation was used to simulate different dosage regimens' $\mathrm{PK} / \mathrm{PD}$ characteristics (ie, $250 \mathrm{mg}$ once-daily [qd], $500 \mathrm{mg} \mathrm{qd}, 1,000 \mathrm{mg} \mathrm{qd}, 2,000 \mathrm{mg}$ qd, $250 \mathrm{mg}$ every 6 hours (q6h), $500 \mathrm{mg}$ q6h, respectively), in order to obtain the best dosing regimen. The cumulative fraction of response (CFR) was calculated to evaluate the efficacy of these regimens, and the results of $\% T>$ MIC were calculated by using the following PK/PD equation: ${ }^{15}$

$$
\% T>\mathrm{MIC}=\ln \left(\frac{\text { Dose }}{\mathrm{Vd} \times \mathrm{MIC}}\right) \times \frac{T_{1 / 2}}{\ln (2)} \times \frac{100}{\mathrm{DI}}
$$

where $\% T>$ MIC is the proportion of time that the free serum concentration exceeds the MIC, ln is the natural logarithm, Dose is the intermittent dose in milligrams, $\mathrm{Vd}$ is the volume of distribution in L, MIC is the minimum inhibitory concentration in $\mathrm{mg} / \mathrm{L}, T_{1 / 2}$ is the half-life in hours, and DI is the dosing interval in hours.

\section{Results}

\section{Determination of MICs}

Table 2 shows the susceptibility test results for the 867 strains, and the MIC interpretive standards of dicloxacillin were usually interpreted according to oxacillin. Dicloxacillin showed poor antibacterial activity against $H$. influenzae and M. catarrhalis, with sensitive rates of $9 \%$ and $2 \%$, respectively. Resistance to dicloxacillin was observed in $7.5 \%$ of CNS isolates and 9.2\% of other Streptococcus isolates, whereas $1.5 \%$ of MSSA was resistant to dicloxacillin. Meanwhile, the MIC50 and MIC90 were lower (0.03 and 0.125, respectively). Less than $25 \%$ of $S$. pneumoniae isolates were susceptible to dicloxacillin.

\section{Monte Carlo stimulation}

In this study, based on the PK data of dicloxacillin oral administration with $250 \mathrm{mg}$ qd, $500 \mathrm{mg}$ qd, 1,000 mg qd, 2,000 mg qd, $250 \mathrm{mg}$ q6h, and $500 \mathrm{mg}$ q6h. ${ }^{12}$ Crystal Ball software was used to perform a 10,000 subject Monte Carlo simulation for PK indices. ${ }^{16}$ Tables 3 and 4 show the $\% T>$ MIC of different dosage regimens and the target attainment rates, respectively. Among the single-dose regimens, $\% T>$ MIC values of $250 \mathrm{mg} \mathrm{qd}, 500 \mathrm{mg}$ qd, $1,000 \mathrm{mg}$ qd, and $2,000 \mathrm{mg}$ qd were achieved $40 \%$ only for dicloxacillin $\mathrm{MIC} \leq 0.125 \mathrm{mg} / \mathrm{L}, \leq 0.25 \mathrm{mg} / \mathrm{L}, \leq 0.5 \mathrm{mg} / \mathrm{L}$, and $\leq 0.1 \mathrm{mg} / \mathrm{L}$, respectively. However, multipledose regimens (250 $\mathrm{mg} \mathrm{q} 6 \mathrm{~h}$ and $500 \mathrm{mg} \mathrm{q} 6 \mathrm{~h}$ ) against the strains with the $\mathrm{MIC} \leq 4 \mathrm{mg} / \mathrm{L}$ and $\leq 8 \mathrm{mg} / \mathrm{L}$ could achieve $40 \%$ of $\% T>$ MIC (Table 3 ). The target attainment rates of regimens $250 \mathrm{mg}$ qd, $500 \mathrm{mg}$ qd, 1,000 mg qd, $2,000 \mathrm{mg} \mathrm{qd}, 250 \mathrm{mg}$ q6h, and $500 \mathrm{mg}$ q6h against isolates with MIC $\leq 0.06 \mathrm{mg} / \mathrm{L}, \leq 0.125 \mathrm{mg} / \mathrm{L}, \leq 0.25 \mathrm{mg} / \mathrm{L}, \leq 0.5 \mathrm{mg} / \mathrm{L}$, and $\leq 4 \mathrm{mg} / \mathrm{L}$, respectively, exceeded $90 \%$ (Table 4 ; Figure 1).

Table 2 Frequency distributions of dicloxacillin MIC against 867 clinical isolates

\begin{tabular}{|c|c|c|c|c|c|c|c|c|c|c|c|c|c|c|c|c|c|c|c|}
\hline \multirow[t]{2}{*}{ Isolates } & \multirow[t]{2}{*}{ Index } & \multicolumn{16}{|c|}{ MIC range (mg/L) } & \multirow{2}{*}{$\begin{array}{l}\text { MIC50 } \\
\text { (mg/L) }\end{array}$} & \multirow{2}{*}{$\begin{array}{l}\text { MIC90 } \\
(\mathrm{mg} / \mathrm{L})\end{array}$} \\
\hline & & $<0.015$ & 0.015 & 0.03 & 0.06 & 0.125 & 0.25 & 0.5 & I & 2 & 4 & 8 & 16 & 32 & 64 & 128 & $>128$ & & \\
\hline Haemophilus & $\mathrm{n}$ & 0 & 0 & 0 & 0 & 0 & 0 & I & 1 & 3 & 9 & 9 & 17 & 6 & 3 & I & 4 & 16 & 64 \\
\hline influenzae & $\mathrm{CN}$ & 0 & 0 & 0 & 0 & 0 & 0 & I & 2 & 5 & 14 & 23 & 40 & 46 & 49 & 50 & 54 & & \\
\hline$(n=54)$ & CP (\%) & 0 & 0 & 0 & 0 & 0 & 0 & 2 & 4 & 9 & 26 & 43 & 74 & 85 & 91 & 93 & 100 & & \\
\hline Moraxella & $\mathrm{n}$ & 0 & I & 0 & 0 & 0 & 0 & 0 & 0 & 0 & 0 & 0 & I & I & 6 & 27 & 20 & 128 & $>128$ \\
\hline catarrhalis & $\mathrm{CN}$ & 0 & 1 & I & I & I & I & I & I & I & I & I & 2 & 3 & 9 & 36 & 56 & & \\
\hline$(n=56)$ & CP (\%) & 0 & 2 & 2 & 2 & 2 & 2 & 2 & 2 & 2 & 2 & 2 & 4 & 5 & 16 & 64 & 100 & & \\
\hline MSSA & $\mathrm{n}$ & 52 & 0 & 273 & 0 & 47 & 6 & 3 & I & 0 & I & I & I & 3 & 0 & 0 & 0 & 0.03 & 0.125 \\
\hline \multirow[t]{2}{*}{$(n=388)$} & $\mathrm{CN}$ & 52 & 52 & 325 & 325 & 372 & 378 & 381 & 382 & 382 & 383 & 384 & 385 & 388 & 0 & 0 & 0 & & \\
\hline & CP (\%) & 13 & 13 & 84 & 84 & 96 & 97 & 98 & 98 & 98 & 99 & 99 & 99 & 100 & 0 & 0 & 0 & & \\
\hline CNS & $\mathrm{n}$ & 36 & 0 & 2 & 0 & 0 & I & 5 & 4 & 1 & I & 0 & 2 & 0 & I & 0 & 0 & $<0.015$ & I \\
\hline \multirow[t]{2}{*}{$(n=53)$} & $\mathrm{CN}$ & 36 & 36 & 38 & 38 & 38 & 39 & 44 & 48 & 49 & 50 & 50 & 52 & 52 & 53 & 0 & 0 & & \\
\hline & $\mathrm{CP}(\%)$ & 68 & 68 & 72 & 72 & 72 & 74 & 83 & 91 & 92 & 94 & 94 & 98 & 98 & 100 & 0 & 0 & & \\
\hline Streptococcus & $\mathrm{n}$ & 0 & I & 4 & 0 & 7 & 12 & 15 & 15 & 8 & 19 & 80 & 82 & 19 & 0 & 0 & 0 & 8 & 16 \\
\hline pneumoniae & $\mathrm{CN}$ & 0 & 1 & 5 & 5 & 12 & 24 & 39 & 54 & 62 & 81 & 161 & 243 & 262 & 0 & 0 & 0 & & \\
\hline$(n=262)$ & CP (\%) & 0 & 0 & 2 & 2 & 5 & 9 & 15 & 21 & 24 & 31 & 61 & 93 & 100 & 0 & 0 & 0 & & \\
\hline Other & $\mathrm{n}$ & 0 & 1 & 5 & II & 1 & 3 & 14 & 12 & 2 & 0 & 4 & 0 & 1 & 0 & 0 & 0 & 0.5 & 2 \\
\hline Streptococcus & $\mathrm{CN}$ & 0 & 1 & 6 & 17 & 18 & 21 & 35 & 47 & 49 & 49 & 53 & 53 & 54 & 0 & 0 & 0 & & \\
\hline isolates $(n=54)$ & $\mathrm{CP}(\%)$ & 0 & 2 & 11 & 31 & 33 & 39 & 65 & 87 & 91 & 91 & 98 & 98 & 100 & 0 & 0 & 0 & & \\
\hline
\end{tabular}

Abbreviations: CN, cumulative number; CNS, coagulase-negative Staphylococcus; CP, cumulative percentage; MIC, minimum inhibitory concentration; MIC50, 50\% of tested isolates were inhibited; MIC $90,90 \%$ of tested isolates were inhibited; MSSA, methicillin-sensitive Staphylococcus aureus. 
Table $3 \% T>$ MIC of dicloxacillin at different dosage regimens

\begin{tabular}{|c|c|c|c|c|c|c|c|c|c|c|}
\hline \multirow[t]{2}{*}{ Dosage regimens } & \multicolumn{10}{|c|}{ MIC (mg/L) } \\
\hline & 0.016 & 0.03 & 0.06 & 0.125 & 0.25 & 0.5 & $\mathbf{I}$ & 2 & 4 & 8 \\
\hline $250 \mathrm{mg}$ qd & $57 \pm 6$ & $52 \pm 5$ & $46 \pm 5$ & $40 \pm 4$ & $35 \pm 3$ & $29 \pm 3$ & $23 \pm 3$ & $17 \pm 2$ & $12 \pm 2$ & $6 \pm 2$ \\
\hline $500 \mathrm{mg}$ qd & $65 \pm 7$ & $59 \pm 6$ & $53 \pm 5$ & $47 \pm 5$ & $4 I \pm 4$ & $35 \pm 3$ & $29 \pm 3$ & $23 \pm 3$ & $17 \pm 2$ & $11 \pm 2$ \\
\hline I,000 mg qd & $73 \pm 7$ & $67 \pm 7$ & $60 \pm 6$ & $54 \pm 5$ & $48 \pm 5$ & $4 I \pm 4$ & $35 \pm 4$ & $29 \pm 3$ & $22 \pm 3$ & $16 \pm 2$ \\
\hline $2,000 \mathrm{mg}$ qd & $87 \pm 9$ & $80 \pm 8$ & $73 \pm 7$ & $66 \pm 7$ & $59 \pm 6$ & $52 \pm 5$ & $45 \pm 4$ & $37 \pm 4$ & $30 \pm 3$ & $23 \pm 3$ \\
\hline $250 \mathrm{mg} \mathrm{q6h}$ & $245 \pm 25$ & $220 \pm 3$ & $1,945 \pm 3$ & $170 \pm 4$ & $145 \pm 3$ & $120 \pm 3$ & $95 \pm 3$ & $71 \pm 3$ & $46 \pm 3$ & $2 I \pm 2$ \\
\hline $500 \mathrm{mg} \mathrm{q6h}$ & $258 \pm 26$ & $234 \pm 23$ & $210 \pm 22$ & $186 \pm 19$ & $162 \pm 16$ & $138 \pm 14$ & $114 \pm 12$ & $90 \pm 10$ & $67 \pm 7$ & $43 \pm 5$ \\
\hline
\end{tabular}

Note: Data are presented as mean \pm SD.

Abbreviations: MIC, minimum inhibitory concentration; qd, once-daily; q6h, every 6 hours.

As shown in Table 5, none of the dosing regimen reached $40 \%$ of CFR against $M$. catarrhalis. Multiple-dose regimens could obtain higher CFR than single-dose regimens against $H$. influenza and S. pneumoniae. However, all dosing regimens against MSSA obtained CFR $\geq 90 \%$. Meanwhile, dosing regimens of 2,000 $\mathrm{mg} q d, 250 \mathrm{mg} q 6 \mathrm{~h}$, and $500 \mathrm{mg}$ q6h could obtain $>90 \%$ of CFR for CNS. For other Streptococcus isolates, multiple-dose regimens achieved CFR $\geq 90 \%$.

\section{Discussion}

Dicloxacillin is a semisynthetic isoxazolyl penicillin antibiotic, which has high $\beta$-lactamase stability and excellent activity against Gram-positive microorganisms. ${ }^{1,5}$ Previous studies have proved that it showed time-dependent bactericidal activity and could be well tolerated in patients and volunteers. ${ }^{12,17}$ Several studies on PK properties of dicloxacillin revealed that it can be rapidly absorbed after oral administration, with the higher serum concentration, absolute bioavailability, and cumulative urinary excretion compared with other isoxazole penicillins, such as oxacillin and cloxacillin..$^{18,19}$ In the present study, we provided the first comprehensive assessment of dicloxacillin dosing regimen against $H$. influenzae, $M$. catarrhalis, MSSA, CNS, S. pneumoniae, and other Streptococcus isolates for Chinese population, in order to optimize the use of dicloxacillin and reduce drug resistance.

Previous publication trial of dicloxacillin in healthy Chinese volunteers provides reference PK parameters for our
Monte Carlo simulation. ${ }^{12}$ They found that $C_{\max }$ and $\mathrm{AUC}_{0-\infty}$ were approximately four times and five times higher in healthy Chinese subjects compared with Western population. ${ }^{12,20}$ Part of that is due to lower body weight of Asian population, resulting in greater dicloxacillin exposure. Thus, it is necessary to apply the individual treatment for Easterners and Westerners, respectively; also worth noting that much of Chinese people live in rural areas and small towns, where county hospitals provide the first medical service most. Our study collected the community-onset strains from various secondary hospitals to estimate the effectiveness of dicloxacillin, in order to provide guidance on the clinical application in county hospitals. In this study, we observed that dicloxacillin has good bactericidal effect against MSSA, CNS, and other Streptococcus isolates. Previous studies proved that dicloxacillin had a significant antibacterial activity against $S$. aureus, S. pneumonia, S. viridans, and S. agalactiae. ${ }^{21-23}$ However, the resistance rate of S. pneumonia is as high as $76.3 \%$ in the present study. Therefore, our results suggest that dicloxacillin had better antibacterial effect against MSSA, CNS, and other Streptococcus infection from the community, but not against infections caused by $H$. influenzae, M. catarrhalis, and S. pneumoniae. Beyond that, the propensity-score-adjusted retrospective cohort studies have demonstrated that 90-day mortality was higher for patients receiving cefuroxime compared with dicloxacillin. ${ }^{6,7}$

In our study, we used Monte Carlo simulation to compare PTA of different dosing regimens of dicloxacillin.

Table 4 PTA of $40 \%$ time above MIC for dicloxacillin at different dosage regimens

\begin{tabular}{|c|c|c|c|c|c|c|c|c|c|c|c|}
\hline \multirow[t]{2}{*}{ Dosage regimens } & \multicolumn{11}{|c|}{ MIC (mg/L) } \\
\hline & 0.016 & 0.03 & 0.06 & 0.125 & 0.25 & 0.5 & $\mathbf{I}$ & 2 & 4 & 8 & 16 \\
\hline $250 \mathrm{mg}$ qd & 99.97 & 99.27 & 91.03 & 51.71 & 7.78 & 0.05 & 0 & 0 & 0 & 0 & 0 \\
\hline $500 \mathrm{mg}$ qd & 100 & 100 & 99.76 & 94.3 & 58.95 & 9.35 & 0.08 & 0 & 0 & 0 & 0 \\
\hline I,000 mg qd & 100 & 100 & 100 & 99.88 & 95.74 & 63.01 & 9.84 & 0.1 & 0 & 0 & 0 \\
\hline $2,000 \mathrm{mg} q \mathrm{~d}$ & 100 & 100 & 100 & 100 & 99.98 & 99.52 & 85.69 & 25.5 & 0.45 & 0 & 0 \\
\hline $250 \mathrm{mg}$ q6h & 100 & 100 & 100 & 100 & 100 & 100 & 100 & 100 & 95.26 & 0 & 0 \\
\hline $500 \mathrm{mg} \mathrm{q6h}$ & 100 & 100 & 100 & 100 & 100 & 100 & 100 & 100 & 100 & 68.29 & 0 \\
\hline
\end{tabular}

Abbreviations: MIC, minimum inhibitory concentration; qd, once-daily; q6h, every 6 hours; PTA, probability of target attainment. 


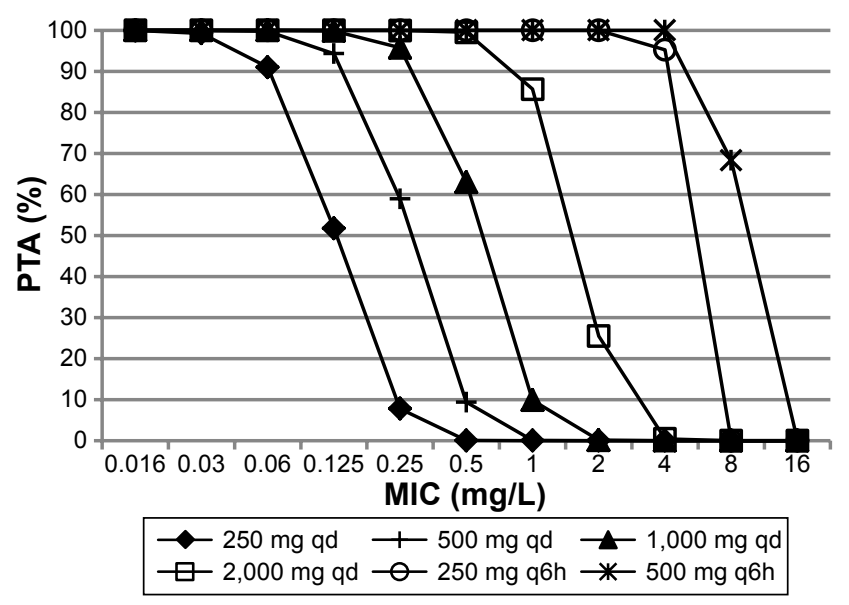

Figure I PTA-MIC curves of dicloxacillin at different dosage regimens. Abbreviations: MIC, minimum inhibitory concentration; PTA, probability of target attainment; qd, once-daily; q6h, every 6 hours.

Monte Carlo simulation incorporates the variability of PK parameters in human and the range of possible MIC values in the given bacterials. The results could predict drug effect more accurately and comprehensively, thereby providing sound scientific evidence for empiric treatment of infection. For the penicillins, $T \%>$ MIC is the optimal $\mathrm{PK} / \mathrm{PD}$ index associated with the drug-related responses. For these agents, optimizing the duration of exposure to effective concentrations could increase the rate or extent of killing. Sandberg et $\mathrm{al}^{24}$ examined the intracellular and extracellular activities of dicloxacillin against two MSSA strains in vitro using macrophages and in vivo by using a mouse peritonitis model. They demonstrated that the $\% T>$ MIC index is best correlated with both intracellular and extracellular infection outcome. Although a value of $\sim 10 \%$ is sufficient for a static effect, a value of $100 \%$ is required to obtain a maximal effect. With estimated mean MICs for penicillin-susceptible $S$. aureus of $0.125 \mathrm{mg} / \mathrm{L}$ for dicloxacillin, the free non-protein-bound plasma drug concentration $\% T>$ MIC would achieve $67 \%$ for dicloxacillin at doses of $1 \mathrm{~g} \mathrm{q} 6 \mathrm{~h} .{ }^{7}$ We found that $\% \mathrm{~T}>\mathrm{MIC}$ of dicloxacillin $250 \mathrm{mg}$ q6h and $500 \mathrm{mg}$ q6h achieved $40 \%$ against the strains with the $\mathrm{MIC} \leq 4 \mathrm{mg} / \mathrm{L}$ and $\leq 8 \mathrm{mg} / \mathrm{L}$. Furthermore, all dosing regimens against MSSA obtained $\mathrm{CFR} \geq 90 \%$. A prospective study indicated that dicloxacillin sodium of $1 \mathrm{~g}$ four times daily or $2 \mathrm{~g}$ three times daily with $\% T>$ MIC of $100 \%$ was superior to $1 \mathrm{~g}$ three times daily with $\% T>$ MIC of $75 \%$ in the treatment of $S$. aureus bacteremia infection. ${ }^{25}$ Therefore, when the dosage and other conditions remain unchanged, shortening the intervals between each drug administration could obtain a satisfactory therapeutic effect.

To our knowledge, our study is the first to address the $\mathrm{PK} / \mathrm{PD}$ target values of different dosage regimens in Chinese patients with community-acquired infection. The findings of this study are positive and encouraging in terms of dicloxacillin against MSSA, CNS, and other Streptococcus isolates by using Monte Carlo simulations, considering as a recurrence of a large number of cases in reality.

\section{Limitations}

However, it also has several limitations. First, the PK parameters of dicloxacillin were obtained from healthy subjects, which is not wholly equal to older population or patients with diseases. In addition, Monte Carlo simulations are a broad class of computational algorithms. Clinical application from our study should be made with caution until a randomized clinical trial could be performed.

\section{Conclusion}

Dicloxacillin has a significant antibacterial activity against MSSA, CNS, and other Streptococcus isolates. Based on $\mathrm{PK} / \mathrm{PD}$ index values from volunteers, Monte Carlo simulations of $250 \mathrm{mg}$ q6h and $500 \mathrm{mg}$ q6h dosing regimens are recommended for clinical applications, especially for communityonset infections. The dosage regimen can be adjusted according to patients' infection status and expected target. Future prospective randomized controlled clinical trials are required to investigate the tolerability and clinical cure rates of dicloxacillin.

Table 5 CFR for dicloxacillin at different dosage regimens

\begin{tabular}{|c|c|c|c|c|c|c|c|c|}
\hline $\begin{array}{l}\text { Dosage } \\
\text { regimens }\end{array}$ & $\begin{array}{l}\text { Haemophilus } \\
\text { influenzae } \\
(n=54)\end{array}$ & $\begin{array}{l}\text { Moraxella } \\
\text { catarrhalis } \\
(n=56)\end{array}$ & $\begin{array}{l}\text { MSSA } \\
(n=388)\end{array}$ & $\begin{array}{l}\text { CNS } \\
(n=53)\end{array}$ & $\begin{array}{l}\text { Streptococcus } \\
\text { pneumoniae } \\
(n=262)\end{array}$ & $\begin{array}{l}\text { Other } \\
\text { Streptococcus } \\
\text { isolates }(n=54)\end{array}$ & $\begin{array}{l}\text { Gram-positive } \\
\text { bacteria } \\
(n=757)\end{array}$ & $\begin{array}{l}\text { Total } \\
(n=867)\end{array}$ \\
\hline $250 \mathrm{mg}$ qd & $0.0 \%$ & $1.8 \%$ & $89.6 \%$ & $71.8 \%$ & $3.6 \%$ & $31.0 \%$ & $54.4 \%$ & $47.6 \%$ \\
\hline 500 mg qd & $0.2 \%$ & $1.8 \%$ & $96.2 \%$ & $73.7 \%$ & $7.7 \%$ & $38.9 \%$ & $59.9 \%$ & $52.4 \%$ \\
\hline $\mathrm{I}, 000 \mathrm{mg}$ qd & $1.4 \%$ & $1.8 \%$ & $97.9 \%$ & $80.2 \%$ & $13.1 \%$ & $57.2 \%$ & $64.4 \%$ & $56.4 \%$ \\
\hline $2,000 \mathrm{mg}$ qd & $4.9 \%$ & $1.8 \%$ & $98.4 \%$ & $89.9 \%$ & $20.6 \%$ & $84.7 \%$ & $69.9 \%$ & $61.5 \%$ \\
\hline 250 mg q6h & $25.1 \%$ & $1.8 \%$ & $98.7 \%$ & $94.3 \%$ & $30.6 \%$ & $90.7 \%$ & $74.2 \%$ & $66.5 \%$ \\
\hline $500 \mathrm{mg}$ q6h & $37.3 \%$ & $1.8 \%$ & $98.9 \%$ & $94.3 \%$ & $51.8 \%$ & $95.8 \%$ & $82.0 \%$ & $74.1 \%$ \\
\hline
\end{tabular}

Abbreviations: CFR, cumulative fraction of response; CNS, coagulase-negative Staphylococcus; MSSA, methicillin-sensitive Staphylococcus aureus; qd, once-daily; q6h, every 6 hours. 


\section{Acknowledgment}

This work was supported by a Key Research and Development Program from Zhejiang Province (2015C03032).

\section{Author contributions}

YHX and WY developed the concept and designed the experiments. JRJ, TTX, and CQY performed the experiments. WY and JRJ performed Monte Carlo simulation. JHF and PS gave conceptual advice. WY wrote the paper. All the authors discussed the results and implications and commented on the manuscript at all stages. All authors contributed toward data analysis, drafting and revising the paper and agree to be accountable for all aspects of the work.

\section{Disclosure}

The authors report no conflicts of interest in this work.

\section{References}

1. Stewart C, Shaver TS, Flournoy DJ, Smith L, Giessmann T, Mohr JA. Methicillin-resistant staphylococcal urinary tract infection treated with dicloxacillin. J Okla State Med Assoc. 1993;86:66-68.

2. Smith LG. Chronic staphylococcal infections of bone and soft tissue. Treatment with dicloxacillin. J Med Soc N J. 1970;67:219-222.

3. Deresinski SC, Stevens DA. Clinical evaluation of parenteral dicloxacillin. Curr Ther Res Clin Exp. 1975;18:151-162.

4. Gravenkemper CF, Bennett JV, Brodie JL, Kirby WM. Dicloxacillin: in vitro and pharmacologic comparisons with oxacillin and cloxacillin. Arch Intern Med. 1965;116:340-345.

5. Marcy SM, Klein JO. The isoxazolyl penicillins: oxacillin, cloxacillin, and dicloxacillin. Med Clin North Am. 1970;54(5):1127-1143.

6. Rasmussen JB, Knudsen JD, Arpi M, Schønheyder HC, Benfield T, Ostergaard C. Relative efficacy of cefuroxime versus dicloxacillin as definitive antimicrobial therapy in methicillin-susceptible Staphylococcus aureus bacteraemia: a propensity-score adjusted retrospective cohort study. J Antimicrob Chemother. 2014;69(2):506-514.

7. Nissen JL, Skov R, Knudsen JD, et al. Effectiveness of penicillin, dicloxacillin and cefuroxime for penicillin-susceptible Staphylococcus aureus bacteraemia: a retrospective, propensity-score-adjusted case-control and cohort analysis. J Antimicrob Chemother. 2013;68:1894-1900.

8. Craig W. Pharmacokinetic/pharmacodynamic parameters: rationale for antibacterial dosing of mice and men. Clin Infect Dis. 1998;26:1-12.

9. Craig WA. Basic pharmacodynamics of antibacterials with clinical applications to the use of beta-lactams, glycopeptides, and linezolid. Infect Dis Clin North Am. 2003;17(3):479-501.

10. Roberts JA, Kirkpatrick CM, Lipman J. Monte Carlo simulations: maximizing antibiotic pharmacokinetic data to optimize clinical practice for critically ill patients. J Antimicrob Chemother. 2011;66(2):227-231.
11. Sy SK, Zhuang L, Derendorf H. Pharmacokinetics and pharmacodynamics in antibiotic dose optimization. Expert Opin Drug Metab Toxicol. 2016;12(1):93-114.

12. Wu G, Zheng Y, Zhou H, et al. Safety and pharmacokinetics of dicloxacillin in healthy Chinese volunteers following single and multiple oral doses. Drug Des Devel Ther. 2015;9:5687-5695.

13. Wattal C, Oberoi JK, Goel N, Raveendran R, Khanna S. Matrix-assisted laser desorption ionization time of flight mass spectrometry (MALDITOF MS) for rapid identification of micro-organisms in the routine clinical microbiology laboratory. Eur J Clin Microbiol Infect Dis. 2017;36:807-812.

14. Clinical and Laboratory Standards Institute. Performance standards for antimicrobial susceptibility testing. 26th informational supplement; 2016. Available from: http://www.clsi.org/. Accessed January 2016.

15. Turnidge JD. The pharmacodynamics of beta-lactams. Clin Infect Dis. 1998;27(1):10-22.

16. Wang Z, Kim S, Quinney SK, Zhou J, Li L. Non-compartment model to compartment model pharmacokinetics transformation meta-analysis-a multivariatenonlinearmixed model. BMCSyst Biol.2010; 4 (Suppl 1):S8.

17. Zamotaev IP, Sokolova VI, Konstantinova LA, Pozdniakova VP. Effektivnost' kapsul dikloksatsillina natrievoĭ soli pri bronkholegochnykh zabolevaniiakh. [Effectiveness of capsules of the sodium salt of dicloxacillin in bronchopulmonary diseases]. Antibiotiki. 1976;21:266-269. Russian.

18. Knott T, Lange A, Volkening R. Dicloxacillin, ein Penicillinase-festes Oralpenicillin. Antibakterielle Wirksamkeit und Pharmakokinetik beim Menschen. [Dicloxacillin, a penicillinase-fast oral penicillin. Antibacterial efficacy and pharmacokinetics in humans]. Arzneimittelforschung. 1965;15:331-340. German.

19. Bennett JV, Gravenkemper CF, Brodie JL, Kirby WM. Dicloxacillin, a new antibiotic: clinical studies and laboratory comparisons with oxacillin and cloxacillin. Antimicrob Agents Chemother (Bethesda). 1964;10:257-262.

20. Alderete O, Gonzalez-Esquivel DF, Del Rivero LM, Castro Torres N. Liquid chromatographic assay for dicloxacillin in plasma. JChromatogr B Analyt Technol Biomed Life Sci. 2004;805:353-356.

21. Bergan T. Penicillins. Antibiot Chemother (1971). 1978;25:1-122.

22. Reimer LG, Stratton CW, Reller LB. Minimum inhibitory and bactericidal concentrations of 44 antimicrobial agents against three standard control strains in broth with and without human serum. Antimicrob Agents Chemother. 1981;19:1050-1055.

23. Dimitrova DJ, Pashov DA, Dimitrov DS. Dicloxacillin pharmacokinetics in dogs after intravenous, intramuscular and oral administration. $J$ Vet Pharmacol Ther. 1998;21:414-417.

24. Sandberg A, Jensen KS, Baudoux P, Van Bambeke F, Tulkens PM, Frimodt-Møller N. Intra- and extracellular activities of dicloxacillin against Staphylococcus aureus in vivo and in vitro. Antimicrob Agents Chemother. 2010;54:2391-2400.

25. Jensen AG, Wachmann CH, Espersen F, Scheibel J, Skinhøj P, FrimodtMøller N. Treatment and outcome of Staphylococcus aureus bacteremia: a prospective study of 278 cases. Arch Intern Med. 2002;162:25-32.
Drug Design, Development and Therapy

\section{Publish your work in this journal}

Drug Design, Development and Therapy is an international, peerreviewed open-access journal that spans the spectrum of drug design and development through to clinical applications. Clinical outcomes, patient safety, and programs for the development and effective, safe, and sustained use of medicines are the features of the journal, which

\section{Dovepress}

has also been accepted for indexing on PubMed Central. The manuscript management system is completely online and includes a very quick and fair peer-review system, which is all easy to use. Visit http://www.dovepress.com/testimonials.php to read real quotes from published authors. 